\title{
Phenolic Antioxidants Identified by ESI-MS from Yerba Maté (Ilex paraguariensis) and Green Tea (Camelia sinensis) Extracts
}

Deborah H. Markowicz Bastos ${ }^{1, *}$, Luciane A. Saldanha ${ }^{1}$, Rodrigo R. Catharino ${ }^{2}$, Alexandra C. H. F. Sawaya ${ }^{2}$, Ildenize B. S. Cunha ${ }^{2}$, Patrícia O. Carvalho ${ }^{3}$ and Marcos N. Eberlin ${ }^{2}$

${ }^{1}$ Nutrition Department, School of Public Health, São Paulo University, Av. Dr. Arnaldo, 715, São Paulo, SP, CEP 01246-904, fax/phone 55-11-30617705, Brazil

2 Thomson Mass Spectrometry Laboratory, Chemistry Institute, State University of Campinas, UNICAMP, Campinas, SP, Brazil; E-mails: rrcatharino@yahoo.com.br, franksawaya@terra.com.br, deninha@yahoo.com.br, eberlin@iqm.unicamp.br

3 School of Pharmacy, São Francisco University, Bragança Paulista, SP, Brazil; E-mail: patcarvalho@saofrancisco.com.br

* Author to whom correspondence should be addressed; E-Mail: dmbastos@usp.br; Phone: (+55)-1130617705, Fax: (+55) 11-20617771

Received: 21 December 2006; in revised form: 3 March 2007 / Accepted: 4 March 2007 /

Published: 12 March 2007

Abstract: Aqueous extracts of green yerba maté (Ilex paraguariensis) and green tea (Camellia sinensis) are good sources of phenolic antioxidants, as already described in the literature. The subject of this study were organic extracts from yerba maté, both green and roasted, and from green tea. Their phenolic profiles were characterized by direct infusion electrospray insertion mass spectrometry (ESI-MS) and their free radical scavenging activity was determined by the DPPH assay. Organic extracts containing phenolic antioxidants might be used as natural antioxidants by the food industry, replacing the synthetic phenolic additives used nowadays. Ethanolic and aqueous extracts from green yerba maté, roasted yerba maté and green tea showed excellent DPPH scavenging activity (>89\%). The ether extracts from green and roasted yerba maté displayed a weak scavenging activity, different from the behavior observed for the green tea ether extract. The main phenolic compounds identified in green yerba maté water and ethanolic extracts were: caffeic acid, quinic acid, caffeoyl glucose, caffeoylquinic acid, feruloylquinic acid, dicaffeoylquinic acid and rutin. After the roasting process two new 
compounds were formed: caffeoylshikimic acid and dicaffeoylshikimic acid. The ethanolic extracts from yerba maté, both roasted and green, with lower content of phenolic compounds (3.80 and $2.83 \mathrm{mg} / \mathrm{mL}$ ) presented high antioxidant activity and even at very low phenolic concentrations, ether extract from GT $(0.07 \mathrm{mg} / \mathrm{mL})$ inhibited DPPH over $90 \%$.

Keywords: Yerba maté (Ilex paraguariensis); Green tea (Camellia sinensis); Phenolic compounds; ESI-MS; Natural antioxidant; Free radical scavenging activity

\section{Introduction}

Many properties of plant products are associated with the presence of phenolic compounds, which are essential for plant development and play an important role in their defense mechanisms. These compounds, present in the regular diet, might be beneficial to human health by lowering the incidence of cancer and cardiovascular diseases [1,2]. They could also be employed in food processing as natural antioxidants in order to prevent lipid peroxidation, one of the main causes of food deterioration [3-6].

Dried leaves of yerba maté (Ilex paraguariensis), a native South American tree, are used to prepare an infusion that is rich in phenolic acids and has shown in vitro and in vivo antioxidant activity, besides other pharmacological properties [7-12]. Dried and roasted maté leaves are also brewed as a tea beverage, but there are no published results related to their in vivo pharmacological effects and only one result relating to in vitro antioxidant activity [13]. Most of the previous published results from yerba maté studies concerned aqueous extracts from green maté. Organic liphophilic extracts from yerba maté having antioxidant activity could be used by the food industry as antioxidants, in replacement of synthetic phenolic antioxidants. Foods that contain high concentrations of pro-oxidant substances (as transition metals, heme-protein) and large amounts of polyunsaturated fatty acids are easily attacked by free radicals and undergo oxidation, which may cause rancidity, decreasing the acceptability and lowering the food nutritional value. To prevent and retard lipid oxidation, synthetic antioxidants such as BHA and BHT are usually employed as preservatives by the food industry. The replacement of these synthetic antioxidants by plant extract sources of natural antioxidants is a public health concern and subject of several research projects [3-6].

Green tea (Camellia sinensis) is a well studied source of polyphenols antioxidants, being the catechins the most abundant among them [14-16]. The free radical scavenging activity measured using the stable free radical 1,1-diphenyl-2-picryl-hydrayl (DPPH) is one of the main tests used to explore the use of herb extracts as antioxidants [17-18]. The DPPH molecule is a stable free radical by virtue of the delocalization of the spare electron over the molecule as a whole, which gives rise to a deep violet color, characterized by an absorption band at about $517 \mathrm{~nm}$. As the odd electron of the radical becomes paired off, in the presence of a hydrogen donor, that is, a free radical scavenging antioxidant, the absorption strength is decreased, and the resulting decolorization is stoichiometric with respect to the number of electrons captured $[17,19,20]$. The results may be expressed as radical scavenging activity or inhibition of free radical in percentages (I \%) where the absorbance of the reaction mixture containing the DPPH free radical and the antioxidant sample (the test extract or a well known 
antioxidant substance as Trolox ${ }^{\circledR}$-a hydrosoluble vitamin E analog-, BHA or BHT, used as “control”) is related to the absorbance of the reaction mixture without any antioxidant (a blank) after an incubation period (usually $30 \mathrm{~min}$ ), using the formula:

$$
\% \mathrm{I}=[(\text { A blank-A sample/A blank }) \times 100]
$$

or expressed as the percentage of the DPPH remaining $\left(\% \mathrm{DPPH}_{\text {rem }}\right)$ calculated as:

$$
\% \mathrm{DPPH}_{\text {rem }}=100 \times[\mathrm{DPPH}]_{\text {rem }} /[\mathrm{DPPH}]_{T=0}
$$

The results may also be expressed using the $\mathrm{IC}_{50}$ parameter, which is defined as the concentration of substrate that causes $50 \%$ loss of the $\mathrm{DPPH}$ activity (color). The $\mathrm{IC}_{50}$ is calculated from a graph plotting inhibition percentage (I \%) against antioxidant concentration.

The free radical scavenging activity depends not only on the phenolic content but also on the type of phenolic compound(s). Phenolic compounds scavenge free radicals through several proposed mechanisms, including delocalization of electrons and formation of intramolecular hydrogen bonds. The redox chemistry of phenolic compounds may describe the chemical reactivity as an electron donor and thus, their antioxidant functionality. This parameter was determined for catechins, gallocatechins, quercitin and rutin by differential pulse voltametry with reference to a saturated calomel electrode [21] and for caffeic, chlorogenic, sinapic, ferulic and p-coumaric acids by cyclic voltammetry on acetate buffer ( $\mathrm{pH}$ 5.6) on glassy carbon and modified glassy electrode [22].

Within this scope, it would be of interest to determine both qualitative and quantitative information about the phenolic compounds present in organic yerba maté and green tea extracts that could be used by the food industry as natural antioxidant additives.

\section{Results and Discussion}

The ESI-MS fingerprints of the ethanolic (Figure 1. I. B) and water (Figure 1. I.C) green yerba maté extracts were qualitatively similar and the following compounds were identified: $\mathrm{m} / \mathrm{z} 179$ caffeic acid, m/z 191 - quinic acid, m/z 341 - caffeoyl glucose, $m / z 353$ - caffeoylquinic acid, m/z 367 feruloylquinic acid, $m / z 515$ - dicaffeoylquinic acid and m/z 609 rutin. As no chromatographic separation was performed, it wasn't possible to determine which isomers of caffeoylquinic acid and dicaffeoylquinic acid were present, but as all isomers are common components of green yerba maté and have antioxidant activity [24], their stereochemistry was not deemed important for this study. The ESI-MS fingerprint of the ethanolic extract of roasted yerba maté (Figure 1 III. B) presented ions corresponding to: $\mathrm{m} / \mathrm{z} 179$ - caffeic acid, $\mathrm{m} / \mathrm{z} 191$ - quinic acid, $\mathrm{m} / \mathrm{z} 353$ - caffeoylquinic acid, $\mathrm{m} / \mathrm{z} 367$ - feruloylquinic acid and $\mathrm{m} / \mathrm{z} 515$ - dicaffeoylquinic acid, which were already present before roasting. It is noteworthy that two compounds not observed before roasting can now be clearly observed: $\mathrm{m} / \mathrm{z} 335$ - caffeoylshikimic acid and m/z 497 - dicaffeoylshikimic acid. These compounds contain one molecule of water less than the analogous caffeoyl- and dicaffeoylquinic acids and have been found previously in dried plums [25]. The ESI-MS fingerprint of the aqueous extract of roasted yerba maté (Figure 1 III. C) presented the ions of: $\mathrm{m} / \mathrm{z} 179$ - caffeic acid, $\mathrm{m} / \mathrm{z} 191$ - quinic acid, $\mathrm{m} / \mathrm{z}$ 335 - caffeoylshikimic acid, and $\mathrm{m} / \mathrm{z} 353$ - caffeoylquinic acid.

The ESI-MS fingerprint of the ethanolic extract of green tea (Figure1.II B) presented the ions of: m/z 289 - catechin and /or epicatechin, m/z 341 - caffeoyl glucose and m/z 441 - epicatechin gallate. 
The ESI-MS fingerprint of the aqueous extract of green tea (Figure 1. II C) presented the ions of: $\mathrm{m} / \mathrm{z}$ 191 - quinic acid, m/z 289 - catechin / epicatechin, m/z 305 - gallocatechin /epigallocatechin, $m / z 341$ - caffeoyl glucose m/z 353 - caffeoylquinic acid, m/z 441 - epicatechin gallate, $\mathrm{m} / \mathrm{z} 457$ epigallocatechin gallate and $\mathrm{m} / \mathrm{z} 609$ - rutin. Once again it was not possible to confirm the identity of isomers without chromatographic separation, although all these compounds have been identified previously in green tea [25-28] and several have known antioxidant activity.

Figure 1. ESI-MS fingerprints of green yerba maté (I), green tea (II) and roasted yerba maté (III): A ) ether, B) ethanolic and C) aqueous extracts.
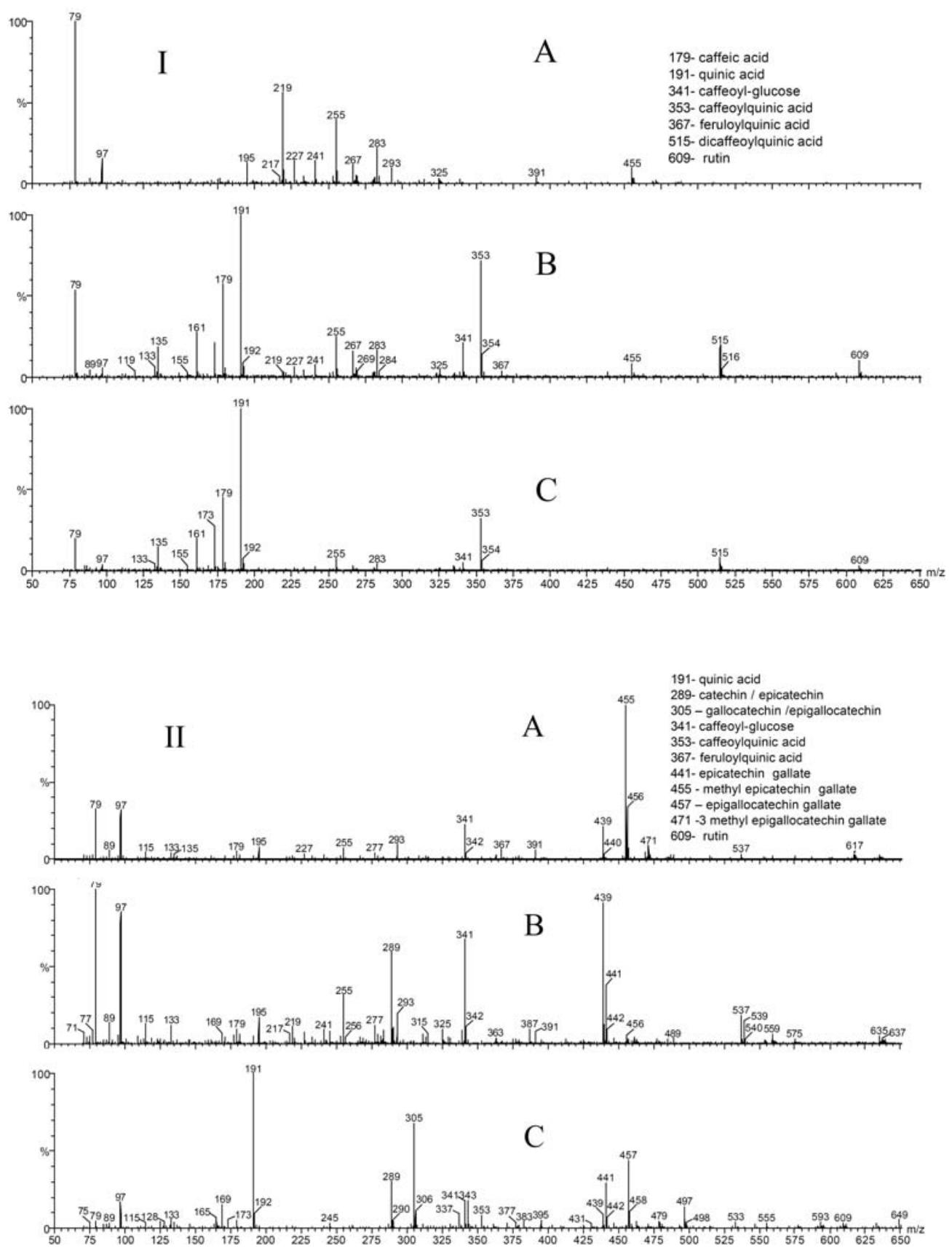
Figure 1. Cont.

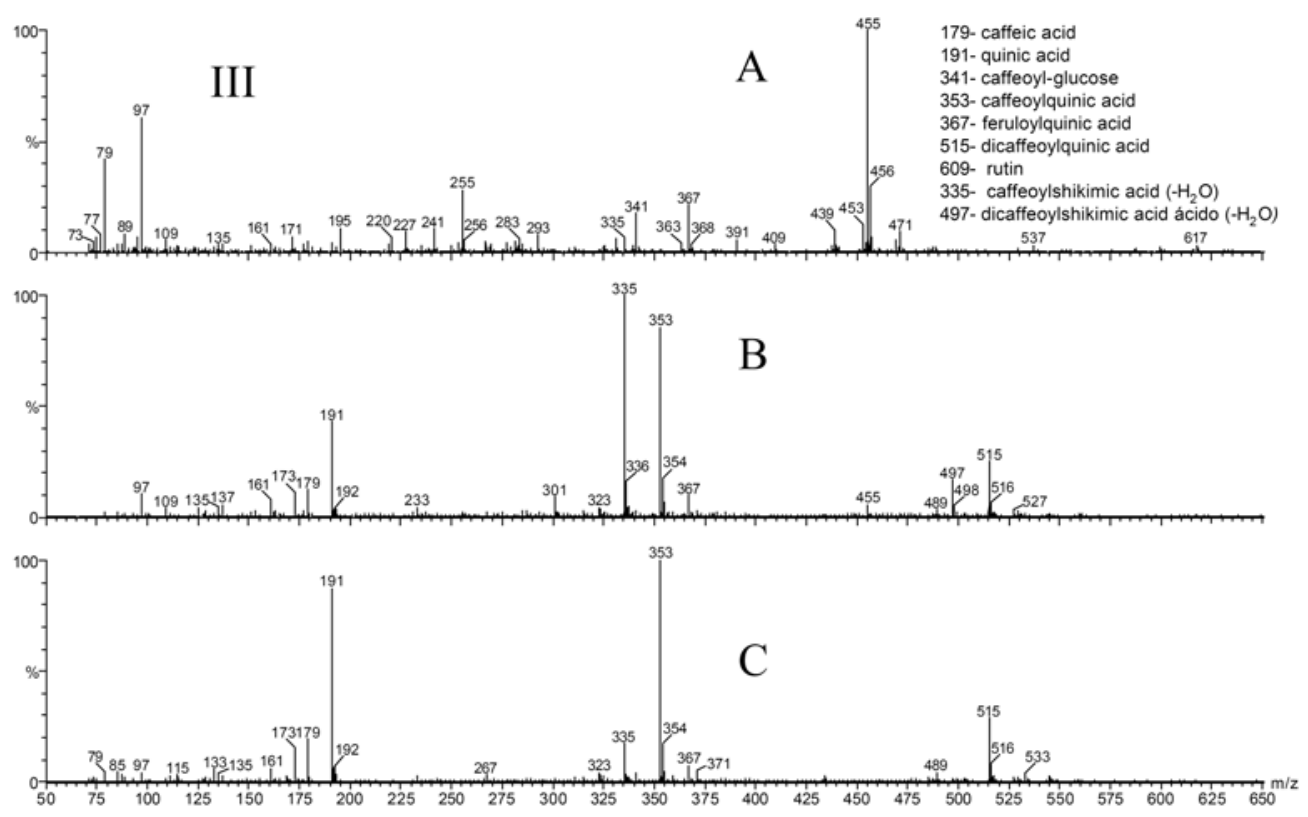

The ESI-MS fingerprint of the ether extract of green yerba maté (Figure 1.I. A) did not present any of the phenolic compounds observed in the other two yerba mate extracts, which possibly explains the low antioxidant activity of this extract. The higher number of ions observed in the ESI-MS fingerprint of the ether extract of roasted yerba maté suggests that some compounds were formed during the process. The ESI-MS fingerprint of the ether extract of roasted yerba maté (Figure 1. III. A) presented the ions of $\mathrm{m} / \mathrm{z} 341$ (caffeoyl glucose) and $\mathrm{m} / \mathrm{z} 367$ (feruloylquinic acid), which weren't observed in the ether extract of green yerba maté (Figure 1.I. A), and help to explain why the ether extract of roasted yerba maté presented a slightly higher (but not significant) antioxidant activity than the ether extract of green yerba maté (Table 1).

Table 1. Phenolic content and free radical (DPPH) scavenging activity of yerba maté (roasted and green) and green tea extracts.

\begin{tabular}{|c|c|c|c|c|c|c|}
\hline & \multicolumn{3}{|c|}{ Phenolic Content (mg/mL) } & \multicolumn{3}{|c|}{ DPPH scavenging activity (I\%)* } \\
\hline & \multicolumn{3}{|c|}{ solvent } & \multicolumn{3}{|c|}{ solvent } \\
\hline & water & ethanol & ether & water & ethanol & ether \\
\hline $\begin{array}{l}\text { Green } \\
\text { maté } \\
(G-Y M)\end{array}$ & $7.73 \pm 0.15^{\mathrm{aA}}$ & $3.80 \pm 0.12^{\mathrm{aB}}$ & $0.02 \pm 0.00^{\mathrm{aC}}$ & $90.45 \pm 0.22^{\mathrm{aA}}$ & $88.93 \pm 0.22^{\mathrm{aA}}$ & $29.47 \pm 3.8^{\mathrm{aB}}$ \\
\hline $\begin{array}{l}\text { Roasted } \\
\text { maté } \\
(R-Y M)\end{array}$ & $6.71 \pm 0.33^{\mathrm{bA}}$ & $2.83+0.07^{\mathrm{bB}}$ & $0.03 \pm 0.0^{\mathrm{aC}}$ & $87.78 \pm 0.76^{\mathrm{bA}}$ & $92.05+0.60^{\mathrm{bA}}$ & $35.38 \pm 3.10^{\mathrm{aB}}$ \\
\hline $\begin{array}{l}\text { Green tea } \\
(G T)\end{array}$ & $7.15 \pm 0.14^{\mathrm{cA}}$ & $13.08 \pm 0.14^{\mathrm{cB}}$ & $0.07 \pm 0.00^{\mathrm{aC}}$ & $88.36 \pm 0.76^{\text {bA }}$ & $92.20 \pm 0.52^{\mathrm{bB}}$ & $91.74 \pm 0.47^{\mathrm{bB}}$ \\
\hline
\end{tabular}

Values are means \pm SD of triplicate samples. Means values with different lowercase letters in the same column and different uppercase letters in the same row are significantly different $(\mathrm{p}<0.05)$. *DPPH scavenging activity of a $0.05 \mathrm{mg} / \mathrm{mL}$ ethanolic BHT solution was $89 \%$ 
The ether extract of green tea showed high free radical scavenging activity, while yerba maté (both green and roasted) ether extracts were less efficient. The free radical scavenging activity of the green tea ether extracts may be due to the phenolic compounds, $\mathrm{m} / \mathrm{z} 341$ - caffeoyl glucose, $\mathrm{m} / \mathrm{z} 367$ feruloylquinic acid, m/z 455 - methyl epicatechin gallate and m/z 471 - 3 methyl epigallocatechin gallate, even at very low concentrations (Table 1, Figure 1.II A). The ESI-MS/MS fragments of the identified compounds are listed in Table 2. The ethanolic extracts of yerba maté, both roasted and green, with lower content of phenolic compounds (3.80 and $2.83 \mathrm{mg} / \mathrm{mL}$ respectively) presented high antioxidant activity (over 88\%). Even at very low phenolic concentration, ether GT extract $(0.07$ $\mathrm{mg} / \mathrm{mL})$ inhibited DPPH over 90\%. Pure antioxidant BHT (0.05 mg/mL) DPPH scavenging activity measured under the same conditions was $89 \%$.

Table 2. ESI-MS/MS fragments of the compounds identified in the extracts of green yerba maté, green tea and roasted yerba maté.

\begin{tabular}{|c|c|c|}
\hline \multicolumn{3}{|c|}{ ESI- MS ions $(\mathrm{m} / \mathrm{z})$} \\
\hline Compound & $\begin{array}{l}\text { Deprotonated } \\
\text { Ions } \\
{[\mathrm{M}-\mathrm{H}]^{-} \mathrm{m} / \mathrm{z}} \\
\end{array}$ & $\begin{array}{c}\text { MS/MS íons } \\
m / z\end{array}$ \\
\hline caffeic acid & 179 & 135,179 \\
\hline quinic acid & 191 & $85,93,111,127,173$ \\
\hline catechin/epicatechin & 289 & 109, 125, 179, 203, 205, 245 \\
\hline caffeoylshikimic acid & 335 & $135,161,179$ \\
\hline caffeoyl glucose & 341 & 119,179 \\
\hline caffeoylquinic acid & 353 & 135, 173, 179, 191 \\
\hline feruloylquinic acid & 367 & $173,191,193$ \\
\hline epicatechin gallate & 441 & 135, 169, 289 \\
\hline methyl epicatechin gallate & 455 & 375,407 \\
\hline epigallocatechin gallate & 457 & 169, 305, 331 \\
\hline 3 methyl epigallocatechin gallate & 471 & 407,441 \\
\hline dicaffeoylshikimic acid & 497 & 161, 179, 335 \\
\hline dicaffeoylquinic acid & 515 & $173,179,191,353$ \\
\hline rutin & 609 & 301 \\
\hline
\end{tabular}

This kind of behavior was also observed with Camellia sinensis products ([19]. The most significant compounds with antioxidant activity in Camellia sinensis leaf are catechins. The content of catechins decreases within the fermentation procedure employed to produce oolong and black tea, and although new phenolic compounds are formed from catechin condensation, the antioxidant activity decreases, indicating that not only the phenolic content responds this property, but the phenolic profile is very important. The ESI-MS fingerprints characterized the different extracts, while ESI-MS/MS allowed the identification of several phenolic compounds. The aqueous and ethanolic extracts of yerba maté contained a greater number of compounds with known antioxidant activity than the ether extracts. Phenolic acids and rutin were the main phenolic compounds in the yerba maté aqueous extracts. All the extracts from green tea were good free radical scavengers. The main phenolic 
identified in these extracts were flavonoids and phenolic acids. The ether green tea extract contained caffeoyl glucose, feruloylquinic acid, methyl epicatechin gallate and 3 methyl epigallocatechin gallate, which may explain the antioxidant activity even at extremely low phenolic content. Lipophilic extracts from green and roasted yerba maté and green tea show antioxidant activity and could be used in the food industry in replacement of synthetic phenolic antioxidants.

\section{Experimental}

\section{General}

Ethanol and ethyl ether were of analytical grade. 5-Caffeoylquinic acid and 2,2-diphenyl-1-picrylhydrazyl radical (DPPH), were purchased from Sigma Aldrich (Steinheim, Germany). Lard was purchased locally. Dried green maté leaves (G-YM), roasted maté leaves (R-YM) and green tea (GT) were obtained from Leão Jr. S/A, a yerba maté producer in Curitiba, Paraná, Brazil in 2005.

\section{Extraction procedure}

The samples (5 g) were extracted continuously for 4 hours in a Soxhlet apparatus with ethanol, ethyl ether or deionized water $(100 \mathrm{~mL})$ at $76^{\circ} \mathrm{C}, 40^{\circ} \mathrm{C}$ and $97^{\circ} \mathrm{C}$ respectively. After the extraction period, the volume was completed to $100 \mathrm{~mL}$ with the appropriate solvent, and the samples kept in amber vessels under nitrogen atmosphere at $-18^{\circ} \mathrm{C}$ until the analyses were performed. All procedures were performed using three independent replicates.

\section{Determination of phenolic content}

Total phenolic content was determined using the Folin-Ciocalteau reagent [23]. Results were expressed as chlorogenic acid equivalents. Phenolic compounds were identified by negative ion mode electrospray mass spectrometry (ESI-MS) fingerprinting. The extracts were analyzed by direct infusion directly into the source by means of a syringe pump (Harvard Apparatus) at a flow rate of 10 $\mathrm{mL} \min ^{-1}$. ESI-MS fingerprints of the extracts and tandem mass spectra (ESI-MS/MS) were acquired in the negative ion mode using a hybrid high-resolution and high-accuracy (5 ppm) Micromass-Waters Q-TOF mass spectrometer (Manchester, UK). Capillary and cone voltages were set to -3000 V and -40 $\mathrm{V}$, respectively, with a desolvation temperature of $100^{\circ} \mathrm{C}$. For tandem mass spectra (ESI-MS/MS) of mass selected compounds, collision energy was optimized for each component, varying from 15 to 50 V. The extracts were diluted in a solution containing $70 \%(\mathrm{v} / \mathrm{v})$ chromatographic grade methanol (Tedia, Fairfield, OH, USA), 30\% (v/v) deionized water and $0.5 \%$ of ammonium hydroxide (Merck, Darmstadt, Germany). The extracts were analyzed by direct insertion negative ion mode ESI-MS fingerprinting. This method provides a sensitive and selective method for the identification of polar organic compounds with acidic sites, such as the phenolic compounds found in yerba maté and green tea. Compounds of interest were then mass selected and their ESI-MS/MS compared to those found in references, for the identification of these compounds [24-28].

Radical DPPH Scavenging Activity 
The free radical scavenging activity was determined using the 2,2-diphenyl-1-picrylhydrazyl radical (DPPH), according to Brand Willians et al. [17]. In brief, each extract (750 $\mu \mathrm{L}$ ) containing 0.05 $\mathrm{mg}$ of soluble solids/mL were added to a methanol solution of DPPH (20 mg/mL, $1.5 \mathrm{~mL})$. After a 30 min incubation period at room temperature, the absorbance was read at $517 \mathrm{~nm}$. The DPPH scavenging activity was expressed as the inhibition of free radical DPPH in percent (I\%) as described by Tepe et al. [29].

$$
I \%=\left(A_{\text {blank }}-A_{\text {sample }} / A_{\text {blank }}\right) \times 100
$$

where $A_{\text {blank }}$ is the absorbance of the control reaction (containing all reagents except the test extract), and $A_{\text {sample }}$ is the absorbance of the test extract. Three replicates tests were carried out for each extract. Papetti et al., 2006 [30] employed the same approach with the name of Antiradical Activity \% . The scavenging capacity was also determined for an ethanolic solution of pure BHT $(0.05 \mathrm{mg} / \mathrm{mL})$ just for comparison purposes.

\section{Statistical Analysis}

All values were reported as mean \pm standard deviation of three different replicates. One-way analysis of variance was carried out using the SPSS system (SPSS, Chicago, IL, USA) and multiple significant differences were determined by Tukey at 5\% level.

\section{Acknowledgements}

The authors are grateful to FAPESP for financial support (project 04/05412-8) and Leão Jr, Curitba, Paraná, Brazil for providing the plant material.

\section{References}

1. Nishino, H.; Murakoshi, M.; Mou, X. Y.; Wada, S.; Masuda, M.; Ohsaka, Y.; Satomi, Y.; Jinno, K. Cancer prevention by phytochemicals. Oncology 2005, 69, 38-40 Suppl. 1.

2. Salka, E. R.; Hanne, F.; Kirstine, S. K.; Lea, P. Dietary proanthocyanidins: Occurrence, dietary intake, bioavailability, and protection against cardiovascular disease. Mol. Nutrit. Food Res. 2000, 49, 159-174.

3. Alligiannis, N.; Mitaku, S.; Tsitsa-Tsardis, E.; Harvala, C.; Tsaknis, I.; Lalas, S.; Haroutounian, S. Methanolic extract of Verbascum macrurum as a source of natural preservatives against oxidative rancidity. J. Agric. Food Chem. 2003, 51, 7308-7312.

4. Dwivedi, S.; Vasavada, M. N.; Cornforth, D. Evaluation of antioxidant effects and sensory attributes of chinese 5-spice ingredients in cooked ground beef. J. Food Sci. 2006, 71, C12-C17.

5. Pérez-Matéos, M.; Lanier, T. C.; Boyd, L. C. Effects of rosemary and green tea extracts on frozen surimi gels fortified with omega-3 fatty acids. J. Sci. Food Agric. 2006, 86, 558-567.

6. Pizzale, L.; Bortolomeazzi, R., Vichi, S., Uberegger, E.; Lanfrando, S.C. Antioxidant activity of sage (Salvia officinalis and S. fruticosa) and oregano (Origanum onitus and O. indercedens) extracts related to their phenolic compound content. J. Sci. Food Agric. 2002, 82, 1645-1651. 
7. Gugliucci, A.; Menini, T. Three different pathways for human LDL oxidation are inhibited in vitro by aqueous extracts of the medicinal herb Achyrocline satureoides Life Sci. 2002, 71, 693705.

8. Gugliucci, A. Antioxidant effects of Ilex paraguariensis: Induction of decreased oxidability of human LDL in Vivo. Biochem. Biophys. Res. Comm. 1996, 224, 338-344.

9. Gugliucci, A.; Stahl, A. J. Low density lipoprotein oxidation is inhibited by extracts of Ilex paraguariensis. Biochem. Mol. Biol. Int. 1995, 35, 47-56.

10. Bracesco, N.; Dell, M.; Rocha, A.; Behtash, S.; Menini, T.; Gugliucci, A.; Nunes, E. Antioxidant Activity of a botanical Extract Preparation of Ilex paraguariensis: Prevention of DNA doublestrand breaks in Saccharomyces cerevisiae and human low-density lipoprotein oxidation. J. Altern Complem. Med. 2003, 9, 379-387.

11. Chandra, S.; Mejia, E. G. Polyphenolic compounds, antioxidant capacity and quinone reductase activity of aqueous extract of Ardisis compressa in comparison to maté (Ilex paraguariensis) and green (Camellia sinesnsis) teas. J. Agric. Food Chem. 2004, 52, 3583-3589.

12. Ramirez-Mares, M.; Chandra, S.; Mejia, E. G. In vitro chemopreventive activity of Camelia sinesnsis, Ilex paraguariensis and Ardisis compressa tea extracts and selected polyphenols. Mutat. Res. 2004, 554, 53-65.

13. Bastos, D. H. M.; Ishimoto, E. Y.; Marques, M. O.; Ferri, A. F.; Torres, E. A. F. Essential oil and antioxidant activity of green maté and maté-tea (Ilex paraguariensis) infusions. J. Food Comp. Anal. 2006, 19 (6-7), 538-543.

14. Nanjo, F.; Goto, K.; Seto, R.; Suzuki, M.; Sakai, M.; Hara, Y. Scavenging effects of tea catechins and their derivatives on 1,1-Diphenyl-2-Picrylhydrazyl radical. Free Rad. Biol. Med. 1996, 6, 895-902.

15. Leung, L. K.; Su, Y.; Chen, R.; Zhang, Z.; Huang, Y.; Chen, Z.Y. Theafalvins in black tea and catechins in green tea are equally effective antioxidants. J. Nutr. 2001, 131, 2248-2251.

16. Yokosawa, T.; Nakagawa, T.; Kitani, K. Antioxidative activity of green tea polyphenol in cholesterol-fed rats. J. Agric. Food Chem. 2002, 50, 3549-3552.

17. Brand-Willians W., Cuvelier M.E., Berset C. Use of a free radical method to evaluate antioxidant activity. Food Sci. Technol. 1995, 28, 25-30.

18. Parejo, I.; Viladomat, F.; Bastida, J.; Rosas-Romero, A.; Saavedra, G.; Murcia, M. A.; Jiménez, M.; Codina, C. Investigation of Bolivian plant extracts for their radical scavenging activity and antioxidant activity. Life Sci. 2003, 73, 1667-1681.

19. Yamaguchi, T.; Takamura, H.; Matoba, T.; Terão, J. HPLC method for evaluation of the free radical scavenging activity of foods by using 1,1-diphenyl-2-picrazylhydrazyl. Biosic. Biotech. Biochem. 1998, 62, 1201-1204.

20. Molyneux, P. The use of stable free radical diphenylpicrylhydrazil(DPPH) for estimating antioxidant activity. J. Sci. Technol. 2004, 26, 211-219.

21. Balentine, D. A.; Wiseman, S. A.; Bouwens, L. C. M. The chemistry of tea flavonoids. Crit. Rev. Food Sci. Nutr. 1997, 37, 693-704.

22. Sousa, W. R.; da Rocha, C.; Cardoso, C. L.; Silva D. H. S.; Zanoni, M. V. B. Determination of the relative contribution of phenolic antioxidants in orange juice by voltammetric methods. J. Food Comp. Anal. 2004, 17 (5), 619-633. 
23. Singleton, V. L.; Rossi., J. A. Colorimetric of total phenolics with phosphomolybidicphosphotungstic acid reagents. Am. J. Enol. Vitic. 1965, 16, 144-158.

24. Carini, M.; Facino, R. M.; Aldini, G.; Calloni, M.; Colombo, L. Characterization of phenolic antioxidants from Maté (Ilex paraguariensis) by liquid chromatography/mass spectrometry and liquid chromatography/Tandem mass spectrometry. Rapid Commun. Mass Spectrom. 1998, 12, 1813-1819.

25. Fang, N.; Yu, S.; Prior, R. Characterization of phenolic constituents in dried plums. J. Agric. Food Chem. 2002, 50, 3579-3585.

26. Sawaya, A. C. H. F.; Tomazela, D. M.; Cunha, I. B. S.; Vassya, S.; Bankova, V. S.; Maria, C.; Marcucci, M. C.; Angela, R.; Custodio, A. R.; Eberlin, M. N. Electrospray ionization mass spectrometry fingerprinting of própolis. Analyst 2004, 129, 739-744.

27. Atoui, A. K.; Mansouri, A.; Boskou, G.; Kefalas, P. Tea and herbal infusions: their antioxidant activity and phenolic profile. Food Chem. 2005, 89, 27-39.

28. Miketova, P.; Schram, K. H.; Whitney, J.; Li, M.; Huang, R.; Kerns, E.; Valcic, S.; Timmermann, B. N.; Rourick, R.; Klohr, S. Tandem mass spectrometry studies of green tea catechins: Identification of three minor components in the polyphenolic extract of green tea. J. Mass Spectr. 2000, 35, 860-869.

29. Tepe, B.; Sokmen, M.; Akpulat, H. A.; Sokmen, A. Screening of the antioxidant potentials of six Salvia species from Turkey. Food Chem. 2006, 95, 200-204.

30. Papetti, A.; Daglia, M.; Aceti, C.; Quaglia, M.; Gregotti, C.; Gazzani, G. Isolation of an in vitro and ex vivo antiradical melanoidin from roased barley. J. Agric. Food Chem. 2006, 54, 12091216.

31. Daglia, M.; Papetti, A.; Gregotti, C.; Berte, F.; Gazzani, G. In vitro antioxidant and ex vivo protective activities of green and roasted coffee. J. Agric. Food Chem. 2000, 48, 1449-1454.

32. Fuster, M. D.; Mitchell, A. E.; Ochi, H.; Shibamoto, T. Antioxidative activities of heterocyclic Compounds Formed in Brewed Coffee. J. Agric. Food Chem. 2000, 48, 5600-5603.

33. Yanagimoto, K.; Lee, K.; Ochi, H.; Shibamoto, T. Antioxidative activity of Heterocyclic compounds found in coffee volatiles produced by Maillard Reaction. J. Agric. Food Chem. 2002, 50, 5480-5484.

34. Morales, F. J.; Babbel, M. B. J. Melanoidins exert a weak antiradical activity in watery fluids. $J$. Agric. Food Chem. 2002, 50, 4657-4661.

35. Delgado-Andrade, C.; Rufian-Henares, J. A.; Morales, F. J. Assessing the antioxidant activity of melanoidins from coffee brews by different antioxidant methods. J. Agric. Food Chem. 2005, 3, 7832-7836.

Sample availability: Contact the authors

(c) 2007 by MDPI (http://www.mdpi.org). Reproduction is permitted for noncommercial purposes. 